\title{
Pricing-Decision and Coordination Contract considering Product Design and Quality of Recovery Product in a Closed-Loop Supply Chain
}

\author{
Qingming Zou ${ }^{1}$ and Guangyu $\mathrm{Ye}^{2}$ \\ ${ }^{1}$ School of Economics and Management, University of South China, Hunan 421001, China \\ ${ }^{2}$ School of Business Administration, South China University of Technology, Guangzhou 510640, China \\ Correspondence should be addressed to Qingming Zou; zqm_234@163.com
}

Received 2 March 2015; Accepted 27 July 2015

Academic Editor: Joaquim Ciurana

Copyright ( 92015 Q. Zou and G. Ye. This is an open access article distributed under the Creative Commons Attribution License, which permits unrestricted use, distribution, and reproduction in any medium, provided the original work is properly cited.

In a closed-loop supply chain consisting of a manufacturer and a retailer, this paper studies the pricing strategies and coordination mechanism of supply chain when the remanufacturing cost is random caused by the proportion of reusability parts in design stage and quality condition of recycling product. The results show that the wholesale price and retail price are negative correlation, while the recycling rate and total profit of supply chain system are positive correlation with the proportion of reusability component designed in new product and quality of recycling product. Moreover, there are conclusions that the wholesale price and retail price are lower while the recycling rate and total profit of supply chain system are higher with centralized decision. Then, in order to coordinate the closed-loop supply chain, this paper develops a revenue-sharing contract, in which the revenue share parameter is determined based on absolute deviation approach. The theoretical results are illustrated by a numerical example.

\section{Introduction}

The closed-loop supply chain (CLSC), which combines recycling of the used product with the production of new product, offers the potential to contribute in environmental improvement and enhance the environmental image of firms and further reduce product cost to gain hypercompetitive business environment. Once put forward, the closed-loop supply chain management has been paid much attention by government, enterprises, and academics. Many countries strengthened the legislation of recycling of waste materials, making some policies which are in favor of recycling of waste materials. The already abundant list of successfully remanufactured products is continuously enriched to include electronic and electric equipment, office automatization machinery, power tools, and vehicle engines and tires. A large number of companies are implementing recycled products remanufacturing, such as Xerox, IBM, Caterpillar, and Michelin.

In the process of remanufacturing, the enterprises' aim is to reap the environmental and economic benefits. However, the economic viability of a recovery program is affected by not only the uncertainty in yield, which takes into account the conversion rates of recycled components to "like-new" products, but also the ambiguity surrounding customer demand [1]. Demand uncertainty is a known problem faced by firms to determine suitable levels of output before demand is known, which is classically known as the "newsboy" problem in operational research literatures [2-4]. The demand uncertainty in CLSC has received much more attention of researchers [5]. But the uncertainty in yield of CLSC is paying less attention to and there are several existing literatures focusing on it. The uncertainty in yield not only impacts the decision of remanufacturing and the profits of firms but also brings forth influence on the cooperation and coordination of supply chain. Galbreth and Blackburn [6] derive optimal acquisition quantities of used products under quality condition uncertainty for different remanufacturing contexts. Robotis et al. [7] considered the impact of uncertainty in remanufacturing cost on rate of recovery used product and investigated the effect of inspection of used production on recycling rate. 
The uncertainty in yield is mainly related with the acquisition and quality condition of recycling used product, the quantity of reusable component, and so on, which all induce the uncertainty of remanufacturing cost. In reality, the uncertainty of remanufacturing cost not only impacts the decision of remanufacturing, just when the cost of remanufacturing is under the cost of new product, and the firm then has motivation to take part in the remanufacturing. It also brings forth influence on the price-decision for the remanufacturing product and new product and the coordination of supply chain. Therefore, firms need to take into consideration factors such as reusability and quality condition of recovery product in CLSC. In the initial design process of a new product, firms should consider the facilitation of disassembly and reusability of component. Of course, there are initial basic cost considerations, since components designed for remanufacturing may be costlier to manufacture but facilitate future recovery and reuse [8]. The proportion of reusable component in new product also impacts the acquisition and collection and brings forth influence on continuous reliable supply of used product to be able to take advantage of remanufacturing in an effective manner. Guide and van Wassenhove [9] pointed out that investments in used product acquisition and collection are quintessential. The quality of recovery used product is another factor influencing the quantity of reusable component. The condition of used product is typically unknown to the firm in advance, and it varies from one product to the other due to difference in usage patterns. This uncertainty has been identified by academics and practitioners as one of the most important challenges for firms to invest in reusability and closed-loop operations [10].

There are several existing pieces of literature considering the influence of uncertainty in yield on remanufacturing. Their focus is on decisions of remanufacturing such as produce plan and control [11], material planning [12], and inventory control [13]. In fact, in CLSC, returns are actually raw material for remanufacturing activities and thus the effective management of their acquisition is highly crucial although it has not attracted the interest of many researches as Guide and van Wassenhove [9] pointed out. One of the few articles in the area of used product acquisition is by Guide et al. [14] who focus on determining the optimal acquisition and selling price for a manufacturer who procures used product that belong to different quality classes and have different remanufacturing costs. Robotis et al. [15] study the optimal remanufacturing and procurement decision for a reseller who collects used products of uncertainty quality that are sold in markets where demand is uncertainty but prices are known. However, the foregoing literatures are only from the manufacturer point of view the uncertainty of remanufacturing cost. In reality, the uncertainty of remanufacturing not only impacts the decision of manufacturer but also brings forth influence on the decision of the buyer and coordination of CLSC. In addition, the uncertainty of remanufacturing cost also can be attributed to the different proportion of reusability component designed in new product. This variety of proportion yet brings about the change of decision of participant in CLSC. It is well known that a fundamental decision for supply chain coordination is pricing, which typically includes wholesale price and retail price. But to the best of our knowledge, there is no article considering the impact of the remanufacturing cost uncertainty on the pricing-decision and performance of closed-loop supply chain.

About supply chain coordination contract, it has been widely studied in the literature, such as returns/buyback policy [16], markdown money [17], revenue-sharing contract [18], and option contract [19]. Much of the literature focused on developing incentive contracts form and did not take into account issues concerning implementation of these contract forms. However, whether a coordination contract can be effectively executed depends on the profit allocation. The ultimate implementation outcomes of a coordinating contract inevitably depend on supply chain members' behavior characteristics, such as risk attitude and fairness preference and negotiating powers. Therefore, how to design a feasible coordinating contract that can be accepted by members in chain is an important issue.

In this paper, we study the influence of the uncertainty of remanufacturing cost induced by quality condition of recovery product and the proportion of reusability component designed in new product on price-decision and recoverydecision of participants in CLSC. We capture the salient characteristic of uncertainty of remanufacturing cost discussed above in a single-period CLSC framework. This paper adopts game theory to investigate the impact of the proportion of reusability component designed in new product and quality condition of recovery on price-decision. We confine our interest to the traditional setting of a bilateral monopoly model in which one manufacturer sells through one retailer. Focusing on static model allows us to develop analytical solutions and insights to key factors including manufacturer wholesale price, retailer price, and the recycling rate. In two different decision models, centrally coordinated model decentralized model, we obtain the manufacturer and the retailer optimal decisions and discuss the threshold of the proportion of reusability component designed in new product when the other conditions are invariant. The sensitivity of impact of parameters on optimal decision also is analyzed. In order to overcome the double marginalization effect and obtain the optimization of system profit in decentralized decision setting, a revenue-sharing contract is designed to coordinate the behavior of members in closed-loop supply chain.

There are two distinguishable differences between this paper and the existing literatures. One is that this paper studies the impact of remanufacturing cost uncertainty induced by the product design and quality condition of recovery product on pricing-decision and performance of CLSC. The quality condition of recovery product is switched to an entrant probability of remanufacturing and the impact on decisions of participant is analyzed. The interaction effect with the proportion of reusability component designed in new product is also discussed. The other is that we comprehensively consider the behavioral characteristics of members in chain and adopt the absolute deviation approach to determine the revenue share parameter of revenue-sharing contract. 
The rest of this paper is organized as follows. In Section 2, we review related literature. In Section 3, the model framework depiction and some basic assumptions are displayed. In Section 4, we construct theory model and, respectively, analyze the manufacturer and the retailer's optimal decisions in two different decision models, centrally coordinated model and decentralized model. In Section 5, The revenue-sharing contract is proposed to coordinate the CLSC. In Section 6, a numerical example is given to show the theoretical results. Concluding remarks are given in Section 7.

\section{Literature Review}

There are a lot of contributions in existing literature that examine alternative policies for production and remanufacturing planning in a CLSC setting, which aim at production planning $[6,7,20-22]$, reversed logistics network design $[11,23,24]$, inventory management $[25,26]$, and supply chain coordination $[27,28]$.

A fundamental decision for supply chain coordination is pricing, which typically includes wholesale price and retail price. In CLSC, Savaskan et al. [27, 28] have studied the manufacturer recycling channels selection by using game theory and found contract coordination methods of remanufacturing closed-loop supply chain. Assuming that each phase of the remanufacturing rate is constant, Ferrer and Swaminathan [29] studied pricing and selling problems of two phases, multiphase and indefinite period of new products and remanufactures under a single manufacturer and duopoly monopolistic conditions, respectively. In a frame of the competition between a new product and remanufactured product manufacturers, Webster and Mitra [30] studied price-making decisions of manufacturers and remanufacturers and analyzed the impact of the recall legislation to remanufacturing. However, the most of above literatures are from the manufacturer point of view the decision of remanufacturing, and the above literatures related to price-decision do not consider the uncertainty in CLSC.

In the closed-loop supply chain operational research, the role of uncertainty has been well-noted in the literature. Fleischmann et al. [31] pointed out that the matching supply and demand is a major challenge in CLSC operation for quantity, quality, and timing of product returns which are unknown in advance. There are some literatures dealt with uncertainty in demand. When the selling price of remanufactured product is Geometric Brownian motion, Liang et al. [32] studied the recycling price. As the market is determined but is not stable (needs will change over time) and the retailer is responsible for the recycling of used product, Lee et al. [33] studied the pricing strategy of the manufacturer and the retailer in the two-level closed-loop supply chain. Ma et al. [34] focus on how consumptionsubsidy influences dual-channel closed-loop supply chain and analyze the channel members' decisions before and after the government-funded program performance, respectively. Fallah et al. [35] study the competition between closedloop chains including manufacturers, retailers, and recyclers in an uncertain environment and investigate the impact of simultaneous and Stackelberg competitions between two closed-loop supply chains on their profits, demands, and returns. The other literatures on managing unknown in quantity and timing of returns in the context of tactical level decision making can be referred to Denizel et al. [36], Ferguson et al. [37], Feng and Viswanathan [22], Qiang et al. [38], and so on. Quality uncertainty has also been considered in existing literature. Aras et al. [39] consider a joint manufacturing and remanufacturing system in which there are different quality classes of returned product that result in a stochastic remanufacturing cost. Zikopoulos and Tagaras [40] examine a case where used products of uncertainty quality can be procured from two collection sites and find conditions under which it is optimal to procure from only one or both sites. In most of those papers related to uncertainty in yield, price and demand are considered exogenous and the focus is on minimizing operational costs. In addition, the influence of proportion of reusability component in new design on pricedecision and recovery-decision is not analyzed.

Our problem is closely related to the literature of joint pricing and recovery decision under uncertainty in yield. Ferrer and Swaminathan [29] and Webster and Mitra [30] consider price-making decisions of manufacturers and remanufacturers in different sites. They do not introduce the uncertainty in model. Liang et al. [32] and Lee et al. [33] introduce the uncertainty in the process of analysis. But they do not consider the uncertainty of remanufacturing cost caused by quality condition of recovery product and the proportion of reusability component designed in new product. Roboits et al. [7] study the investment of inspection of quality condition of recovery product and discussed the optimal proportion of reusability component designed in new product. However, they only consider the decision from the manufacturer's point of view the remanufacturing and do not analyze the impact of this uncertainty of remanufacturing cost owing to quality condition of recovery product proportion of reusability component designed in new product on price-decision of CLSC.

This paper is also closely related to the literature on supply chain coordination with contract and supply chain negotiation. A larger body of literature has explored how to coordinate supply chain with all kinds of popular contracts, such as return policy [16], markdown money [17], revenuesharing contract [18], and option contract [19]. Cachon and Lariviere [41] compared revenue-sharing contracts to several other contracts that enhance channel coordination, for example, buy-back contracts, quantity discounts contracts, and sales-rebate contracts. Zhang et al. [42] investigated how to coordinate a one-manufacturer-two-retailers supply chain with demand disruption by revenue-sharing contract. However, much of the literature on revenue-sharing contract has focused on developing a contract forms and only discussing the feasible region of revenue share, not giving a specific method to determine the revenue share. Moreover, in CLSC, there are few literatures concerning the revenue-sharing contracts. In a downside-risk closed loop supply chain consisting of a risk-neutral, a downside-risk retailer, and two third-party logistics suppliers, Govindan and Popiuc [43] explored the implications of recycling on the reverse supply chain from an efficiency perspective for all 
participants and designed a revenue sharing contract to coordinated the supply chain. Shi et al. [44] analyzed the impact of revenue-and-expense contract and showed that the contract may not coordinate the supply chain. They designed a risk-sharing contract which is composed of revenue-andexpense contract and return policy and proved that the contract can accomplish the channel coordination. In this paper, when the remanufacturing cost is uncertainty, we develop a revenue-sharing contract and give an approach to determine the revenue share.

\section{Model Description and Assumption}

Consider a CLSC with one manufacturer and one retailer in which the manufacturer not only produces new goods with raw materials but also recycles the used products for remanufacturing and the retailer sells only the manufacture's brand within the product class. The new goods is all made by raw material and the remanufacturing product is made by portion of new material and portion of recycling used components. It is assumed that there exist no difference of the quality, function, utilization, the mode of entering market, and the consumers' cognition between the new and remanufacturing product. This assumption is often adopted in some CLSC literatures such as Savaskan et al. [27, 28]. The retailer is responsible for the recycling of used product. The unit price of recovery product is $A$ payed to the consumer and the retailer obtain the unit subsidy $B(B>A)$ charged to the manufacturer. Let $\lambda \in[0,1)$ be the rate of recovery product, which can be thought as the percentage of the total product sales in market. Similar to Savaskan et al. [27, 28], the fixed investment of recycling used product is assumed to be $I=c_{0} \lambda^{2}$, where $c_{0}$ denotes the parameter of scale. It is obvious that $\partial I / \partial \lambda \geq 0, \partial^{2} I / \partial \lambda^{2} \geq 0$, which means that the fixed investment is augmented and the growth rate of investment is speeded up with the increasing recycling rate. The manufacturer wholesale price for unit product is $w$ charged to the retailer. The unit retail price is $p_{1}$. The product demand is price-dependent and is assumed to be $q=\alpha-\beta p_{1}$, where $\alpha$ reflects the extent to which the product will be accepted by the market and $\beta$ represents the sensitive coefficient of the demand responsiveness to the selling price.

In order to increase the potential saving from remanufacturing, the manufacturer's investment in reusability of product is assumed to be one of firms' development strategies. Then it involves a fixed cost incurred before the product is introduced to the market. The amount of this investment cost depends on the extent of reusability built into the design of the new product. Let $\rho$ represent the portion of the product that is designed to be reused $(0 \leq \rho \leq 1)$. In this paper, it is referred to as proportion of reusability component designed in new product, which can be thought as the percentage of the product that will be recovered and reused in future. The extra cost owing to the design effort is assumed to be contained in the unit manufacturing cost. This assumption is also feasible because the extra cost can be shared by all new products. In addition, this paper focuses on the price-decision not on the optimal proportion of reusability component designed in new product; the impact of design effort on price-decision can be reflected in the variant of unit cost of new product and can not be affected by an additional fixed cost. Therefore, the fixed extra cost due to design effort is assumed to be negligible for the tractable analysis and simplifying the exposition of our results in this paper.

Due to the difference of quality condition of recycling used product, not all returned units are considered suitable for remanufacturing. In order to obtain the accurate information of the quality condition of recovery product, all of recycling used products are individually inspected, and only those with remanufacturing cost less than the manufacturing cost are allowed to enter the remanufacturing process. Those recycling used products which do not enter the remanufacturing process are sold to other firms by the manufacturer and the unit product salvage is $c_{d}<B$. The extra inspection cost is assumed to be negligible for the extra cost which can be shared by all remanufacturing products.

The design effort and quality condition of recovery product give rise to the uncertainty in the remanufacturing cost. We model remanufacturing cost uncertainty, which is a proxy for uncertainty in quality of the returns, by assuming that the cost to remanufacture a product is random. Let $c_{r}$ be the cost to remanufacture a product when $\rho=1$, that is, when the whole product is remanufactured. The $c_{r}$ is assumed to be distributed normally with cdf $F\left(c_{r}\right)$, pdf $f\left(c_{r}\right)$, mean $\mu$, and variance $\sigma^{2}$. For a meaningful problem, we assume that the mean $\mu$ is enough high so that the distribution does not have negative support; that is, $P\left(c_{r} \leq 0\right) \rightarrow 0$. In the sequel, we use the probability of recovery product entering to remanufacturing process, which is mainly related with the variance of the remanufacturing cost, as the measure of quality condition uncertainty (a higher uncertainty in the quality condition of returns implies a higher $\sigma$ and a lower probability entering to remanufacturing process and vice versa). Let $c_{m}$ denote the cost to manufacture a new product from raw material. As in prevalent literature, it is assumed that on average the cost for remanufacturing a product is less than that for manufacturing a new one; that is, $c_{m}>E\left(c_{r}\right)=\mu$.

In the CLSC, the manufacturer and the retailer take the Stackelberg game. The manufacturer is the leader of game and the retailer is the follower of game. They all are assumed to be risk neutral and pursue profit maximization. The information is complete.

\section{Model Construction and Solution}

4.1. Model Construction. According to the description and assumptions in Section 3, we know that the remanufacturing cost uncertainty is caused by quality condition of recycling product. In addition, the proportion of reusability component designed in new product also impacts the remanufacturing cost. We assume that the cost to remanufacture the reusable $\rho$ portion of the product increases linearly in $\rho$ and it is given by $\rho c_{r}$ and there is a linear relationship between how much material will be reused and the effort to reuse these material into "as new" product. Therefore, if $\rho$ portion of the product is reused, the cost to produce a remanufactured product denoted as $c_{r m}$ can be given by $c_{r m}=\rho c_{r}+(1-\rho) c_{m}$. All of the recovery products are 
inspected individually, and only those with remanufacturing cost less than the manufacturing cost are allowed to enter the remanufacturing process. Note that this happens with

$$
\begin{aligned}
P\left(c_{r m} \leq c_{m}\right) & =P\left(\rho c_{r}+(1-\rho) c_{m} \leq c_{m}\right) \\
& =P\left(c_{r} \leq c_{m}\right) .
\end{aligned}
$$

Therefore, the random remanufacturing cost is then

$$
c_{r m}=\rho\left[c_{r} \mid c_{r} \leq c_{m}\right]+(1-\rho) c_{m},
$$

where $\left[c_{r} \mid c_{r} \leq c_{m}\right.$ ] follows a truncate normal distribution with pdf $f\left(c_{r}\right) / F\left(c_{m}\right)$ and mean $E\left(c_{r} \mid c_{r} \leq c_{m}\right)=$ $\left(\int_{0}^{c_{m}} c_{r} f\left(c_{r}\right) d c_{r}\right) / F\left(c_{m}\right)$ and $F(\cdot)$ is cdf of normal distribution. The average cost to produce a remanufactured version of the product is $E\left[c_{r m} \mid c_{r} \leq c_{m}\right]=\rho E\left[c_{r} \mid c_{r} \leq c_{m}\right]+(1-\rho) c_{m}$.

Due to the heterogeneity of quality condition of recovery products, just only portion of the total amount of recovery products $\lambda\left(\alpha-\beta p_{1}\right)$ can be used to produce remanufacturing product. Let $s$ denote this quantity. It is obvious that $s$ is a random variable. Since each return product is independently classified as remanufacturable with probability $P=P\left(c_{r} \leq\right.$ $\left.c_{m}\right)$, hence, $s$ follows a binomial distribution with population $\lambda\left(\alpha-\beta p_{1}\right)$ and success probability $P$. The $P$ is related to the $\mu$ and the variance $\sigma^{2}$ of $c_{r}$. When $\mu$ is fixed, $P$ reflects the change of variance $\sigma^{2}$, that is, the heterogeneity of quality of recovery product. Then, when a remanufactured product is produced, the manufacturer can obtain the average revenue $\Delta=\left(c_{m}-E\left(c_{r m} \mid c_{r} \leq c_{m}\right)\right) P+c_{d}(1-P)-B$. It is clear that only when $\Delta>0$, the manufacturer has motivation to recycle the used product for remanufacturing.

According to above analysis, when we use $P$ to represent the quality condition of recycling product, the profit function of the manufacturer can be display as follows:

$$
\begin{aligned}
\pi_{m}(w \mid s)= & \left(w-c_{m}\right)\left(\alpha-\beta p_{1}\right) \\
& +\left(c_{m}-E\left(c_{r m} \mid c_{r} \leq c_{m}\right)\right) s \\
& -B \lambda\left(\alpha-\beta p_{1}\right)+c_{d}\left(\lambda\left(\alpha-\beta p_{1}\right)-s\right) .
\end{aligned}
$$

The profit function of the retailer is

$$
\begin{aligned}
\pi_{r}\left(p_{1}, \lambda \mid s\right)= & \left(p_{1}-w\right)\left(\alpha-\beta p_{1}\right) \\
& +(B-A) \lambda\left(\alpha-\beta p_{1}\right)-c_{0} \lambda^{2} .
\end{aligned}
$$

In the sequel of the paper, the superscripts " $c$," " $d$," "cs," and "*," respectively, stand for the centralized decision, decentralized decision, and coordination decision and the optimal solution. The subscripts " $m$," " $r$," and " $m+r$," respectively, the manufacturer, the retailer, and the whole closed-loop supply chain system.

4.2. Decisions in Decentralized Setting. When the two participants make decisions independently, the decision process can be modeled as a sequential, noncooperative game, with the manufacturer as the leader and the retailer as the follower. The manufacturer determines the wholesale price $w$ charged to the retailer so that the profit of the manufacturer is the most optimal. On the basis of the wholesale price, the retailer determines the retail price $p_{1}$ charged to the consumer and the rate of recycling product $\lambda$. This decision structure is a Stackelberg game and the solution of this game is called the Stackelberg equilibrium. In order to obtain the Stackelberg equilibrium by backward induction, we first solve the retailer's optimal problem when the manufacturer's decision variable $w$ is given. Namely, the equilibrium solutions of the manufacturer and the retailer can be obtained by solving the following optimization problem:

$$
\begin{array}{ll}
\max _{w} & E \pi_{m}(w)=\left(w-c_{m}-\Delta \lambda\right)\left(\alpha-\beta p_{1}\right), \\
\text { s.t. } & p_{1}, \lambda=\arg \max \pi_{r}, \\
& \pi_{r} \\
& =\left(p_{1}-w\right)\left(\alpha-\beta p_{1}\right)+(B-A) \lambda\left(\alpha-\beta p_{1}\right) \\
& -c_{0} \lambda^{2} .
\end{array}
$$

It is easily shown that $\pi_{r}\left(\lambda, p_{1}\right)$ is a concave function with respect to $\lambda, p_{1}$. Therefore, by the first-order conditions

$$
\begin{gathered}
\frac{\partial \pi_{r}}{\partial \lambda}=0, \\
\frac{\partial \pi_{r}}{\partial p_{1}}=0,
\end{gathered}
$$

the response function of the retailer is obtained as follows:

$$
\begin{aligned}
\lambda & =\frac{(\alpha-\beta w)(B-A)}{4 c_{0}-\beta(B-A)^{2}}, \\
p_{1} & =\frac{2 c_{0} \beta w+2 c_{0} \alpha-\alpha \beta(B-A)^{2}}{4 c_{0} \beta-\beta^{2}(B-A)^{2}} .
\end{aligned}
$$

Substitute $\lambda$ and $p_{1}$ into (5), and let $\gamma=4 c_{0}-\beta(B-A)^{2}-$ $\beta \Delta(B-A)$, by the first-order condition $\partial E \pi_{m} / \partial w=0$. The optimal wholesale price is

$$
w^{* d}=\frac{\left(\alpha+\beta c_{m}\right)\left(4 c_{0}-\beta(B-A)^{2}\right)-2 \alpha \beta \Delta(B-A)}{2 \beta \gamma} .
$$

Substitute $w^{* d}$ into the response function of the retailer; the optimal retail price and recycling rate are displayed, respectively, as

$$
\begin{aligned}
p_{1}^{* d} & =\frac{3 c_{0} \alpha-\alpha \beta(B-A)^{2}-\alpha \beta \Delta(B-A)+c_{0} c_{m} \beta}{\beta \gamma}, \\
\lambda^{* d} & =\frac{\alpha-\beta c_{m}}{2 \gamma} .
\end{aligned}
$$

Then, the optimal expected profit of the manufacturer and the optimal profit of the retailer are, respectively,

$$
\begin{aligned}
E \pi_{m}^{* d} & =\frac{c_{0}\left(\alpha-\beta c_{m}\right)^{2}}{2 \beta \gamma} \\
\pi_{r}^{* d} & =\frac{c_{0}\left(\alpha-\beta c_{m}\right)^{2}\left(4 c_{0}-\beta(B-A)^{2}\right)}{4 \beta \gamma^{2}} .
\end{aligned}
$$


The total profit of the CLSC is

$$
\begin{aligned}
& \pi^{* d} \\
& =\frac{c_{0}\left(\alpha-\beta c_{m}\right)^{2}\left(12 c_{0}-3 \beta(B-A)^{2}-2 \beta \Delta(B-A)\right)}{4 \beta \gamma^{2}} .
\end{aligned}
$$

Theory 1. (1) When the quality condition of recovery product is fixed, the proportion of reusability component designed in new product should satisfy $1>\rho>\left(B-c_{d}(1-P)\right) / P\left(c_{m}-E\left(c_{r} \mid\right.\right.$ $\left.\left.c_{r} \leq c_{m}\right)\right)$.

(2) When the proportion of reusability component designed in new product $\rho$ is fixed, the quality condition, which is the probability entering to the remanufacturing for the recovery product, should satisfy $1>P>\left(B-c_{d}\right) /\left(\rho\left(c_{m}-\right.\right.$ $\left.\left.E\left(c_{r} \mid c_{r} \leq c_{m}\right)\right)-c_{d}\right)$.

(3) In order to guarantee the existence of solution for (5) and $0 \leq \lambda^{* d} \leq 1$ hold, the positive constant $c_{0}$ should satisfy

$$
\begin{aligned}
c_{0}>\max \left(\frac{\beta(B-A)^{2}}{2},\right. \\
\left.\frac{2 \beta(B-A)^{2}+\left(2 \beta \Delta+\alpha-\beta c_{m}\right)(B-A)}{8}\right) .
\end{aligned}
$$

Proof. In the light of $\Delta>0$, the conclusions (1) and (2) are easily shown.
Consider $p_{1}^{* d}-w^{* d}=\left(\alpha-\beta c_{m}\right)\left(2 c_{0}-\beta(B-A)^{2}\right) / 2 \beta \gamma$ and $1 \geq \lambda^{* d}=(B-A)\left(\alpha-\beta c_{m}\right) / 2 \gamma \geq 0$. The conclusion (3) in Theory 1 holds.

The conclusions (1) and (2) in Theory 1 demonstrate that when the quality condition of recovery product is uncertainty, the manufacturer needs to consider the proportion of reusability component designed in new product $\rho$. Only when $\rho$ is over a certain level which is correlated to the quality condition, the manufacturer has enthusiasm to use the recovery product to remanufacturing. Similarly, when the proportion of reusability component designed in new product $\rho$ is fixed, the quality condition of recovery product does not be the poor; otherwise, the manufacturer has no interesting in remanufacturing.

To the simplicity of analysis without loss generality and the length of article, in the sequel of the paper, the parameters $c_{0}$ and $\Delta$ do not be discussed again and always are assumed that they can guarantee the existence of optimal solution and $0 \leq \lambda^{* d} \leq 1$. In terms of the above optimal solutions $w^{* d}$, $p_{1}^{* d}$, and $\lambda^{* d}$, we have the following.

Proposition 2. In the decision-decentralized setting, the manufacturer's wholesale price $w^{* d}$ and the retailer's retail price $p_{1}^{* d}$ all decrease while the recycling rate increases as the quality condition of recovery product increases.

Proof. Because

$$
\begin{aligned}
& \frac{\partial w^{* d}}{\partial P}=\frac{-(B-A)\left(4 c_{0}-\beta(B-A)^{2}\right)\left(\alpha-\beta c_{m}\right)\left(\rho\left(c_{m}-E\left(c_{r} \mid c_{r} \leq c_{m}\right)\right)-c_{d}\right)}{2 \gamma^{2}}<0, \\
& \frac{\partial p_{1}^{* d}}{\partial P}=\frac{-c_{0}(B-A)\left(\alpha-\beta c_{m}\right)\left(\rho\left(c_{m}-E\left(c_{r} \mid c_{r} \leq c_{m}\right)\right)-c_{d}\right)}{\gamma^{2}}<0, \\
& \frac{\partial \lambda^{* d}}{\partial P}=\frac{\beta(B-A)^{2}\left(\alpha-\beta c_{m}\right)\left(\rho\left(c_{m}-E\left(c_{r} \mid c_{r} \leq c_{m}\right)\right)-c_{d}\right)}{2 \gamma^{2}}>0,
\end{aligned}
$$

Proposition 2 holds.

Proposition 2 demonstrates that the quality condition of recovery product impacts the pricing strategies and recycling decision of manufacturer and the retailer in CLSC. The better the quality condition of the recovery product, the more the component entering to the remanufacturing and the lower the average cost of new products and remanufactured product. Hence, the wholesale price and retail price decrease as the quality condition of recovery product increases. In the meantime, it is profitable to use the recovery product to produce remanufactured product. The manufacturer has high enthusiasm to recycle used product for remanufacturing, which prompts the retailer to take more efforts to recycle waste products. Therefore, the recycling rate will increase.

Proposition 3. In the decision-decentralized setting, the manufacturer's wholesale price $w^{* d}$ and the retailer's retail price $p_{1}^{* d}$ all decrease while the recycling rate increases as the proportion of reusability component designed in new product $\rho$ increases.

Proof. Because

$$
\begin{aligned}
& \frac{\partial w^{* d}}{\partial \rho}=\frac{-(B-A)\left(4 c_{0}-\beta(B-A)^{2}\right)\left(\alpha-\beta c_{m}\right)\left(\rho\left(c_{m}-E\left(c_{r} \mid c_{r} \leq c_{m}\right)\right)-c_{d}\right)}{2 \gamma^{2}}<0, \\
& \frac{\partial p_{1}^{* d}}{\partial \rho}=\frac{-c_{0}(B-A)\left(\alpha-\beta c_{m}\right)\left(\rho\left(c_{m}-E\left(c_{r} \mid c_{r} \leq c_{m}\right)\right)-c_{d}\right)}{\gamma^{2}}<0,
\end{aligned}
$$




$$
\frac{\partial \lambda^{* d}}{\partial \rho}=\frac{\beta(B-A)^{2}\left(\alpha-\beta c_{m}\right)\left(\rho\left(c_{m}-E\left(c_{r} \mid c_{r} \leq c_{m}\right)\right)-c_{d}\right)}{2 \gamma^{2}}>0
$$

Proposition 3 holds.

Proposition 3 indicates that when other conditions are fixed, the higher the proportion of reusability component designed in new product, the larger the percentage of recycling used components entering to remanufacturing. Then, the average cost of making product will decrease and the manufacturer's wholesale price also decreases. According to the lower wholesale price, the retailer decides a lower retail price to consumers. Then, the market demand of the product will enlarge and the basis of reusable used components will also augment. In the meantime, as it is profitable to use recycling used product to produce remanufactured products, the manufacturer has a strong wish to recycle more and more used product for remanufacturing. In the same way, it is beneficial to recycle more used product for the retailer; therefore, he (or she) is willing to take more efforts to recycle the used product. The recycling rate will increase.

Proposition 4. The optimal expected profit $E \pi_{m}^{* d}$ of the manufacturer and the optimal profit $\pi_{r}^{* d}$ are all increased as the quality condition of recovery product and the proportion of reusability component designed in new product increase, respectively.

Proof. According to formulas of $E \pi_{m}^{* d}$ and $\pi_{r}^{* d}$, it is known that $E \pi_{m}^{* d}$ and $\pi_{r}^{* d}$ are decreasing functions with respect to $\gamma$, and $\gamma$ is a decreasing function with respect to $\rho, P$, respectively. Therefore, in terms of the monotonicity rule of composite function, we know that $E \pi_{m}^{* d}$ and $\pi_{r}^{* d}$ are increasing function with respect to $\rho, P$, respectively.

Proposition 4 implies that the larger the proportion of reusability component designed in new product and the better the quality condition of recovery product, the larger the saving cost due to use the recovery product to produce remanufactured product and the manufacturer and the retailer getting more revenue from remanufacturing actions. the manufacturer and the retailer have stronger enthusiasm to recycle used product. This not only improves the economic benefits of the manufacturer and the retailer but also saves raw material and natural resources and improves the environmental and social benefits.

4.3. Decisions in Centralized Setting. In this subsection, we assume that the manufacturer and the retailer are vertically integrated and the central decision maker determines all decisions (the retail price and recycling rate) to maximize the supply chain profit $\pi_{m+r}$. The optimal decision can be obtained through solving the following optimization problem:

$$
\begin{aligned}
\max _{\lambda, p_{1}} E \pi_{m+r}\left(\lambda, p_{1}\right)= & \left(p_{1}-c_{m}\right)\left(\alpha-\beta p_{1}\right) \\
& +\Delta^{\prime} \lambda\left(\alpha-\beta p_{1}\right)-c_{0} \lambda^{2},
\end{aligned}
$$

where $\Delta^{\prime}=\Delta+B-A$. It is easily shown that $\pi_{m+r}\left(\lambda, p_{1}\right)$ is a concave function with respect to $\lambda, p_{1}$. Therefore, by the first-order conditions

$$
\begin{aligned}
& \frac{\partial E \pi_{m+r}}{\partial \lambda}=0 \\
& \frac{\partial E \pi_{m+r}}{\partial p_{1}}=0
\end{aligned}
$$

the optimal recycling rate, the optimal retail price, the optimal sales, and the optimal profit of CLSC are expressed as

$$
\begin{aligned}
\lambda^{* c} & =\frac{\left(\alpha-\beta c_{m}\right) \Delta^{\prime}}{4 c_{0}-\beta \Delta^{\prime 2}}, \\
p_{1}^{* c} & =\frac{2 c_{0}\left(\alpha-\beta c_{m}\right)-\alpha \beta \Delta^{\prime}}{4 \beta c_{0}-\beta^{2} \Delta^{\prime 2}}, \\
q^{* c} & =\frac{2 c_{0}\left(\alpha-\beta c_{m}\right)}{4 c_{0}-\beta \Delta^{\prime 2}}, \\
\pi_{m+r}^{* c} & =\frac{c_{0}\left(\alpha-\beta c_{m}\right)^{2}}{4 \beta c_{0}-\beta^{2} \Delta^{\prime 2}} .
\end{aligned}
$$

Proposition 5. In the centralized-decision setting, $\lambda^{* c}, p_{1}^{* c}$, $q^{* c}$, and $E \pi_{m+r}^{* c}$ are all increased as the quality condition of recovery product and the proportion of reusability component designed in new product increase, respectively.

Similar to the proof of Propositions 3 and 4, Proposition 5 can be shown which holds by differentiating $\lambda^{* c}, p_{1}^{* c}, q^{* c}$, and $E \pi_{m+r}^{* c}$ with respect to $P$ and $\rho$, respectively. The proof is omitted. Proposition 5 demonstrates that the pricingdecision of product, the recycling efforts, the product sales, and the profit of system are all affected by the quality condition of recovery product and the proportion of reusability component designed in new product. It is consistent with the intuition that the quality condition of recovery product and the proportion of reusability component designed in new product impact the average cost of products and further impact the retail price of product. Thus, the product sales and the expected profit of system are also affected. The basis of reusability component and the recycling efforts are accordingly affected.

Comparing the results of the centralized-decision setting and the decentralized-decision setting, we have the following conclusions.

Proposition 6. (1) One has $p_{1}^{* c}>p_{1}^{* d}, q^{* c}>q^{* d}, \lambda^{* c}>\lambda^{* d}$, (2) $E \pi_{m+r}^{* c}-(4 / 3)\left(E \pi_{m}^{* d}+\pi_{r}^{* d}\right)>0$. 
Proof. (1) Consider

$$
\begin{aligned}
p_{1}^{* c}-p_{1}^{* d} & =\frac{-c_{0}\left(\alpha-\beta c_{m}\right)\left(4 c_{0}+\beta \Delta \Delta^{\prime}\right)}{\beta \gamma\left(4 c_{0}-\beta \Delta^{\prime 2}\right)}<0, \\
q^{* c}-q^{* d} & =\frac{c_{0}\left(\alpha-\beta c_{m}\right)\left(4 c_{0}+\beta \Delta \Delta^{\prime}\right)}{\gamma\left(4 c_{0}-\beta \Delta^{\prime 2}\right)}>0, \\
\lambda^{* c}-\lambda^{* d} & =\frac{4 c_{0} \Delta+2 \beta \Delta^{\prime}(B-A)+\Delta^{\prime}\left(4 c_{0}+\beta \Delta \Delta^{\prime}\right)}{2 \gamma\left(4 c_{0}-\beta \Delta^{\prime 2}\right)} \\
& >0 .
\end{aligned}
$$

Thus, the conclusions in (1) hold. Thus,

According to Theory 1 , we have $\gamma>0,2 c_{0}>\beta(B-A)^{2}$.

$$
\begin{aligned}
& E \pi^{* c}-\frac{4}{3}\left(E \pi_{m}^{* d}+\pi_{r}^{* d}\right)=\frac{1}{3 \gamma^{2}\left(4 c_{0}-\beta \Delta^{\prime 2}\right)} \cdot\left\{4 c_{0}(\alpha\right. \\
& \left.-\beta c_{m}\right) \Delta\left[(B-A)\left(4 c_{0}-\beta(B-A)^{2}\right)\right. \\
& \left.\left.+\Delta\left(6 c_{0}-\beta \Delta(B-A)-2 \beta(B-A)^{2}\right)\right]\right\}>0
\end{aligned}
$$

Therefore, the conclusion in (2) holds.

Proposition 6 indicates that comparing with the centralized structure scenario of closed-loop supply chain decentralized-decision setting has a higher retail price, a lower market demand, and the recycling rate. For these reasons, the optimal system profit of CLSC is not achieved in the decentralized-decision setting, and the relative value of the whole supply chain profit loss, namely, the efficiency loss, is more than $25 \%$. This shows that only the two firms coordinate with each other, then the recycling rate and the product sales will increase, and the system profit also will improve, yet the retail price will decrease and the goal of win-win will be achieved. Thus, it is necessary to design a cooperation and coordination mechanism so that the efficiency of supply chain will improve when the two participants independently make decisions which aimed to maximize their own profit.

\section{A Revenue-Sharing Coordination Contract}

According to the above analysis in Section 4, we know that the decentralized supply chain has a lower profitability than the centralized supply chain at absence of supply chain competition. That is, there exist the so-called double marginalized effects of supply chain. That is, coordinating the behavior of the member firms can improve the performance. Revenue-sharing contracts have been proven to be effective in improving supply chain performance. Through a rigorous empirical analysis, Mortimer [45] pointed out that the adoption of revenue-sharing contracts has increased the industry's total industry profits by $7 \%$. Cachon and Lariviere [41] compared revenue-sharing contracts to several other contracts that enhance channel coordination, for example, buy-back contracts, quantity discounts contracts, and salesrebate contracts. None of these contracts matches revenuesharing contracts' ability to coordinate a wide range of supply chains. Therefore, in this paper, we introduce a revenuesharing contract to coordinate the behavior of the member firms in CLSC so that the performance of decentralized supply chain can achieve that of centralized supply chain.

A revenue-sharing contract usually includes two parameters. The first is the wholesale unit price $w$ that the retailer pay. The second is the revenue share of retailer represented by $\phi(\phi \in(0,1))$. As the manufacturer is leader of game, he (she) offers a revenue-sharing contract $(w, \phi)$ to induce the retailer to replicate the optimal recycling rate and the optimal product sales and the optimal system profit of centralized supply chain. Thus, how to determine the wholesale unit price and the revenue share of retailer is a critical issue.

In CLSC, the average income obtained by sold per unit product is

$$
p_{1}-c_{m}+\Delta^{\prime} \lambda-\frac{c_{0} \lambda^{2}}{\alpha-\beta p_{1}}
$$

Once the the revenue share of retailer is determined, the manufacturer should determine the wholesale unit price as follows:

$$
w=(1-\phi)\left(p_{1}-c_{m}+\Delta^{\prime} \lambda-\frac{c_{0} \lambda^{2}}{\alpha-\beta p_{1}}\right)+c_{m}-\Delta \lambda
$$

Substitute $\lambda^{* c}, p_{1}^{* c}$ into (22); the optimal wholesale price under the revenue-sharing coordination contract is

$$
w^{* c s}=\frac{(1-\phi)\left(\alpha-\beta c_{m}\right)\left(4 c_{0}-\beta \Delta^{\prime 2}\right)+2 c_{m} \beta\left(4 c_{0}-\beta \Delta^{\prime 2}\right)-2 \beta \Delta \Delta^{\prime}\left(\alpha-\beta c_{m}\right)}{2 \beta\left(4 c_{0}-\beta \Delta^{\prime 2}\right)} .
$$

By this time, we have $E \pi_{m}^{* c s}=(1-\phi) E \pi^{* c}, \pi_{r}^{* c s}=\phi E \pi^{* c}$.

In order to ensure that both the manufacturer and the retailer are willing to participate in a cooperative rather than a leader-follower relationship, the revenue-sharing contracts are acceptable to participants in CLSC only if $\pi_{r}^{* c s} \geq \pi_{r}^{* d}$, $\pi_{m}^{* c s} \geq E \pi_{m}^{* d}$, Then, we have the following.
Theory 7. In order to achieve the goal of coordinating the behavior of member firms in CLSC, the revenue-sharing parameter $\phi$ should satisfy $1 / 4 \leq \phi \leq 1 / 2$.

Theory 7 indicates that when the revenue share parameter $\phi \in[1 / 4,1 / 2]$, the revenue-sharing contracts can ensure 
the manufacturer and the retailer to get more profit under cooperative game than under the Stackelberg game. However, the revenue-sharing contracts can not ensure each participant of game to satisfy the coordinating results; that is, it can not ensure each participant to take part in the coordinating action. If a participant does not satisfy with the division of the extra profit owing to cooperative decision, the coordination of supply chain has a risk of breakdown. Therefore, in order to achieve the final goal to achieve the performance of centralized supply under cooperative game, we not only consider the win-win result of contract coordination but also should consider the satisfaction with coordination outcomes among the members in CLSC. Whether a coordination contract can be effectively executed to a large extent depends on the revenue share parameter. Thus, it is an important issue to put forward an appropriate revenue share in design of revenue-sharing coordination contract.

It is difficult to determine precisely the values of revenue share without any further information. However, the manufacturer and the retailer will put forward theirs revenue share in favor of their own interests, and this bargaining outcomes will give us some information to determine an appropriate revenue share. The bargaining outcomes may reflect some factors, for example, the risk attitude and the fairness preference of the manufacturer and the retailer, impacting their satisfaction with results of coordinating actions. The manufacturer and the retailer have different evaluation about the coordination contracts; consequently, the coordinating performance will be affected. Thus, when the revenue-sharing is designed, both opinions of the manufacturer and the retailer about the revenue share should be taken into account. Only in this way, then an appropriate revenue share is put forward and can be accepted by both sides, that is, the manufacturer and the retailer. In this paper, based on the absolute deviation approach, the satisfactions of the manufacturer and the retailer about various kinds of revenue-sharing coordination projects are comprised and then we give a reasonable revenue share so that the members in chain can accept the coordination results.

Assume that there exist several different revenue share projects between the manufacturer and the retailer and denote the revenue share as $\phi_{j}=\left(\phi_{1 j}, \phi_{2 j}\right), j=1,2, \ldots, k$, where $\phi_{1 j}, \phi_{2 j}$, respectively, represent the revenue share of the manufacturer and the retailer in the $j$ th coordination project. The most of all the manufacturers and the retailers want revenue share to be $\phi^{*}=\left(\phi_{1}^{*}, \phi_{2}^{*}\right)$ and $\phi_{i}^{*}=\max _{j}\left\{\phi_{i j}\right\}, i=$ 1,2 represents the manufacturer and the retailer, respectively. The last thing is that the manufacturer and the retailer want revenue share to be $\phi_{*}=\left(\phi_{1 *}, \phi_{2 *}\right)$ and $\phi_{i *}=\min _{j}\left\{\phi_{i j}\right\}$, $i=1,2$. Let $D_{j}^{+}=\sum_{i=1}^{2}\left|\phi_{i}^{*}-\phi_{i j}\right|, D_{j}^{-}=\sum_{i=1}^{2}\left|\phi_{i *}-\phi_{i j}\right|$ be the positive deviation and the negative deviation of the $j$ th project. $D_{j}^{+}, D_{j}^{-}$, respectively, reflect the revenue share divergence between the actual bargaining outcomes and the most of all, and the last thing is that the manufacturer and the retailer want revenue share to be in $j$ th project. In some extent, the magnitudes of $D_{j}^{+}, D_{j}^{-}$can measure the satisfaction with the performance of the $j$ th project. We define the total satisfaction degree of the manufacturer and the retailer about the performance of the $j$ th project as $M_{j}=D_{j}^{+} /\left(D_{j}^{+}+D_{j}^{-}\right)$. It is clear that the larger the ratio is, the closer the revenue share of $j$ th coordination project is to the most of all that the manufacturer and the retailer want. According to the definition of total satisfaction with $j$ th project, the relative size of the satisfaction of $j$ th project among all possible coordination projects can be expressed as $\delta_{j}=M_{j} / \sum_{n=1}^{k} M_{k}$. Then, the reasonable revenue share parameters can be determined as $\phi_{i}=\sum_{j=1}^{k} \delta_{j} \phi_{j i}$, $i=1,2$. This approach determining the revenue share parameters comprehensively considers the behavior of the two parties, that is, the manufacturer and the retailer. In reality, the success of a coordination project depends on the bargaining outcomes, which is closely relevant to the behavior of participant. This approach considers the both sides' opinions about the allocation of the extra profits and its feasibility is illustrated by a specific example.

In some existed literatures related to design contract to coordinate supply chain, the Nash bargaining model is often employed to deal with the division of incremental profits. Nash's bargaining model predicts that the revenue-sharing contract that the retailer and manufacturer both agree to implement maximizes the product of each members' utility over their own disagreement, which, herein, is represented by the profit level under the wholesale price mechanism. In the following segment, taking into account supply members' risk performance and negotiating powers and according to the above suggested approach determining the revenue share, we discuss the determination of revenue share by Nash's bargaining model.

For ease of exposition, we denote

$$
\begin{aligned}
& \widetilde{\Delta} \pi_{r}(\phi)=\phi \pi^{* c}-\pi_{r}^{* d}, \\
& \widetilde{\Delta} \pi_{m}(\phi)=(1-\phi) \pi^{* c}-\pi_{m}^{* d},
\end{aligned}
$$

where $\widetilde{\Delta} \pi_{r}(\phi)$ and $\widetilde{\Delta} \pi_{m}(\phi)$ correspond to the additional split by the retailer and the manufacturer from $\widetilde{\Delta} \pi$, which are their own increased profits from coordination with the revenue-sharing contract associated with revenue share $\phi$. $\tilde{\Delta} \pi=\pi^{* c}-\left(\pi_{m}^{* d}+\pi_{r}^{* d}\right)$ corresponds to the total extra profit from coordination. Since the remanufacturing cost is random, $\widetilde{\Delta} \pi$ must be uncertain for any revenue-sharing contract. Assume that such uncertainty is represented by the probability distribution of $\widetilde{\Delta} \pi$ and the retailer is consistent with the manufacturer with respect to the probability distribution of $\widetilde{\Delta} \pi$. We suppose that both the retailer and the manufacturer have risk preference toward the profit share from $\widetilde{\Delta} \pi$ and their preference can be presented by Von Neumann and Morgenstern's (vN-M) utility function [46], which is assessed by their preference over lotteries involving $\left(\widetilde{\Delta} \pi_{r}(\phi), \widetilde{\Delta} \pi_{m}(\phi)\right)$. Let $U_{r}\left(\widetilde{\Delta} \pi_{r}\right)$ and $U_{m}\left(\widetilde{\Delta} \pi_{m}\right)$ be the retailer's and the manufacturer's vN-M utility function, respectively.

Assume that there are the following two kinds of Nash's bargaining model.

Case 1. Consider a CLSC consisting of a single manufacturer and a single retailer in which they have almost same control 
power over the chain, and the retailer's utility function is $U_{r}\left(\widetilde{\Delta} \pi_{r}\right)=\widetilde{\Delta} \pi_{r}$ and the manufacturer's is $U_{m}\left(\widetilde{\Delta} \pi_{m}\right)=$ $\widetilde{\Delta} \pi_{m}$. Nash's bargaining solution is obtained by solving the following optimization problem:

$$
\begin{array}{ll}
\max _{\phi} & U_{m}\left(\widetilde{\Delta} \pi_{m}\right) U_{r}\left(\widetilde{\Delta} \pi_{r}\right) \\
& =\left(\phi \pi^{* c}-\pi_{r}^{* d}\right)\left((1-\phi) \pi^{* c}-\pi_{m}^{*} d\right), \\
\text { s.t. } & \phi_{\max }=\frac{\pi^{* c}-\pi_{m}^{* d}}{\pi^{* c}} \geq \phi \geq \frac{\pi_{r}^{* d}}{\pi^{* c}}=\phi_{\min } .
\end{array}
$$

It is easy to obtain the optimal revenue share $\phi^{*}=$ $\left(\phi_{\max }+\phi_{\min }\right) / 2$. Case 1 indicates that when the retailer and the manufacturer have almost same control power over chain and are risk-neutral or both are equally risk-averse, they will split the extra profit $\widetilde{\Delta} \pi$ in equal proportions. However, although they both sides have almost power, each one of both participants may still think that the divergence of control power on chain should be considered in the division of extra profit.

Case 2. Consider the divergence of both sides in control power over chain, we introduce the relative importance degree, which is often used in AHP evaluation decision, to measure the relative strength of their control power. Denote the relative importance degree of the retailer and the manufacture as $\eta_{1}$ and $\eta_{2}$, respectively, which $\eta_{1}+\eta_{2}=$ $1, \eta_{1}>0$, and $\eta_{2}>0$. A larger $\eta$ indicates a stronger control power over chain. The retailer's utility function is $U_{r}\left(\widetilde{\Delta} \pi_{r}\right)=\left(\widetilde{\Delta} \pi_{r}\right)^{\eta_{1}}$ and the manufacturer's is $U_{m}\left(\widetilde{\Delta} \pi_{m}\right)=$ $\left(\widetilde{\Delta} \pi_{m}\right)^{\eta_{2}}$. Nash's bargaining solution is obtained by solving the following optimization problem:

$$
\begin{array}{ll}
\max _{\phi} & U_{m}\left(\widetilde{\Delta} \pi_{m}\right) U_{r}\left(\widetilde{\Delta} \pi_{r}\right) \\
& =\left(\phi \pi^{* c}-\pi_{r}^{* d}\right)^{\eta_{1}}\left((1-\phi) \pi^{* c}-\pi_{m}^{*} d\right)^{\eta_{2}}, \\
\text { s.t. } & \phi_{\max }=\frac{\pi^{* c}-\pi_{m}^{* d}}{\pi^{* c}} \geq \phi \geq \frac{\pi_{r}^{* d}}{\pi^{* c}}=\phi_{\min } .
\end{array}
$$

By a simple calculation, we obtain the optimal revenue share $\phi^{*}=\eta_{1} \phi_{\max }+\eta_{2} \phi_{\min }$. Consequently, the expected profit obtained by the retailer is $\pi_{r}\left(\phi^{*}\right)=\pi_{r}^{* d}+\eta_{1} \widetilde{\Delta} \pi$ and the expected profit obtained by the manufacturer is $\pi_{m}\left(\phi^{*}\right)=$ $\pi_{m}^{* d}+\eta_{2} \widetilde{\Delta} \pi$. Case 2 implies that when the retailer and the manufacturer consider the divergence of both sides in control power over chain, they will split the extra according to the relative importance degree. Case 2 also demonstrates that when the retailer and the manufacturer are risk-averse with the Pratt-Arrow risk aversion functions [47], they will split the extra profit in risk-aversion ratio similar to the relative importance degree in Case 2.

The above Cases 1 and 2 all can coordinate the supply chain. However, not all of both sides of the retailer and the manufacturer may agree to the same scheme, and then we should consider a compromise project so that the goal of coordinating the supply chain can be achieved. According to the above proposed approach determining the revenue share, we can obtain the total satisfaction degree of the manufacturer and the retailer about the performance of Cases 1 and 2 , respectively, and then the relative size of the satisfaction of Cases 1 and 2 also can be obtained. Then, the revenue share, which may be accepted by both the manufacturer and the retailer, will be achieved for comprehensively taking into account opinions of both sides. Thus, the suggested approach for revenue share is feasible in practice.

\section{Numerical Studies}

This section provides some numerical examples. Let $\alpha=$ 1600, $\beta=5, c_{0}=8000, c_{m}=200, B=30, A=26$, and $c_{d}=24$. First, we investigate the impact of the proportion of reusability component designed in new product on decisionmaking in CLSC. Assume the random remanufacturing cost $c_{r} \sim N\left(100,30^{2}\right)$. At this time, the probability of $c_{r} \leq 0$ is 0.00043 . Let $\rho=0.3,0.4$, and 0.5 and the revenue share of the retailer $\phi=0.25,0.30,0.35,0.40,0.45$, and 0.50 . In terms of the formulas in Section 4, the optimal solutions under the three kinds of decision mode are displayed in Table 1.

Table 1 provides experimental evidence to support the viewpoint that when the quality condition of recycling product is fixed, the recycling rate, the profits of the manufacturer, and the retailer and the total profit of supply chain are positive correlation while the wholesale price and the retail price are negative correlation with the proportion of reusability component designed in new product. Moreover, there are conclusions that the wholesale price and retail price are lower while the recycling rate and quantity of recycling product and total profit of supply chain system are higher with centralized decision. In addition, when $\phi \in[1 / 4,1 / 2]$, the total profit of supply chain system under the partnership game is equal to that of supply chain in centralized-decision setting, and the profits of the manufacturer and the retailer are not lower than that of them in decentralized-decision setting. This indicates that the consultative revenue sharing mechanism can improve the performance of closed-loop supply chain and achieve the coordination of supply chain.

Secondly, we study the influence of quality condition of recovery product on decision-making in CLSC. Because the quality condition of recovery product is presented by a probability $P$, which reflects the possibility of a recycling product entering into the remanufacturing. The probability $P$ is associated with the mean and the variance of normal distribution, and the variance reflects the fluctuation of quality condition. Thus, we fix $\mu=100$ and $\rho=0.4$, and let $\sigma=40,80$, and 120. According to the results in Section 4, the optimal solutions under the three kinds of decision mode are displayed in Table 2. Table 2 shows that when the proportion of reusability component designed in new product is fixed, the experimental results are consistent with the conclusions about quality condition of recycling product.

To further analyze the influence of the proportion of reusability component designed in new product and quality condition of recovery product on decision-making in CLSC, let $\rho \in[0.3,1], P \in[0.3,0.9]$ and the other conditions are fixed. In decentralized-decision setting, the change trend 
TABLE 1: The optimal solution under the three kinds of decision mode with various proportions of reusability component.

\begin{tabular}{|c|c|c|c|c|c|c|c|c|c|}
\hline \multirow{2}{*}{$\rho$} & \multirow{2}{*}{ Variables } & \multirow{2}{*}{$\begin{array}{l}\text { Decentralized- } \\
\text { decision model }\end{array}$} & \multirow{2}{*}{$\begin{array}{l}\text { Centralized-decision } \\
\text { model }\end{array}$} & \multicolumn{6}{|c|}{ Revenue-sharing model } \\
\hline & & & & $\phi=0.25$ & $\phi=0.30$ & $\phi=0.35$ & $\phi=0.40$ & $\phi=0.45$ & $\phi=0.5$ \\
\hline \multirow{7}{*}{$\rho=0.3$} & $\omega$ & 260.0801 & - & 245.0747 & 242.0747 & 239.0747 & 236.0747 & 233.0747 & 230.0747 \\
\hline & $p_{1}$ & 289.9649 & 259.9673 & 259.9673 & 259.9673 & 259.9673 & 259.9673 & 259.9673 & 259.9673 \\
\hline & $q$ & 150.1753 & 300.1635 & 300.1635 & 300.1635 & 300.1635 & 300.1635 & 300.1635 & 300.1635 \\
\hline & $\lambda$ & 0.0751 & 0.0376 & 0.0376 & 0.0376 & 0.0376 & 0.0376 & 0.03766 & 0.0376 \\
\hline & $\pi_{m}\left(\times 10^{3}\right)$ & 9.0133 & - & 13.5068 & 12.605 & 11.705 & 10.804 & 9.9038 & 9.0033 \\
\hline & $\pi_{r}\left(\times 10^{3}\right)$ & 4.4992 & - & 4.5040 & 5.4045 & 6.3050 & 7.2055 & 8.1060 & 9.0065 \\
\hline & $\pi_{T}\left(\times 10^{4}\right)$ & 1.3513 & 1.8010 & 1.8010 & 1.8010 & 1.8010 & 1.8010 & 1.8010 & 1.8010 \\
\hline \multirow{7}{*}{$\rho=0.4$} & $\omega$ & 259.8901 & - & 244.6189 & 241.6189 & 238.6189 & 235.6189 & 232.6189 & 229.6189 \\
\hline & $p_{1}$ & 289.8697 & 259.5481 & 259.5481 & 259.5481 & 259.5481 & 259.5481 & 259.5481 & 259.5481 \\
\hline & $q$ & 150.6513 & 302.2595 & 302.2595 & 302.2595 & 302.2595 & 302.2595 & 302.2595 & 302.2595 \\
\hline & $\lambda$ & 0.0753 & 0.1323 & 0.1323 & 0.1323 & 0.1323 & 0.1323 & 0.1323 & 0.1323 \\
\hline & $\pi_{m}\left(\times 10^{3}\right)$ & 9.0428 & - & 13.603 & 12.696 & 11.790 & 10.883 & 9.9760 & 9.0693 \\
\hline & $\pi_{r}\left(\times 10^{3}\right)$ & 4.5278 & - & 4.5324 & 5.4392 & 6.3460 & 7.2527 & 8.1595 & 9.0663 \\
\hline & $\pi_{T}\left(\times 10^{4}\right)$ & 1.3571 & 1.8136 & 1.8136 & 1.8136 & 1.8136 & 1.8136 & 1.8136 & 1.8136 \\
\hline \multirow{7}{*}{$\rho=0.5$} & $\omega$ & 259.6990 & - & 243.1717 & 240.1717 & 237.1717 & 234.1717 & 231.1717 & 228.1717 \\
\hline & $p_{1}$ & 289.7739 & 258.6288 & 258.6288 & 258.6288 & 258.6288 & 258.6288 & 258.6288 & 258.6288 \\
\hline & $q$ & 151.1303 & 306.8658 & 306.8658 & 306.8658 & 306.8658 & 306.8658 & 306.8658 & 306.8658 \\
\hline & $\lambda$ & 0.0756 & 0.2303 & 0.2303 & 0.2303 & 0.2303 & 0.2303 & 0.2303 & 0.2303 \\
\hline & $\pi_{m}\left(\times 10^{3}\right)$ & 9.0725 & - & 13.811 & 12.890 & 11.970 & 11.049 & 10.128 & 9.2079 \\
\hline & $\pi_{r}\left(\times 10^{3}\right)$ & 4.5567 & - & 4.6011 & 5.5217 & 6.4423 & 7.3628 & 8.2834 & 9.2040 \\
\hline & $\pi_{T}\left(\times 10^{4}\right)$ & 1.3629 & 1.8412 & 1.8412 & 1.8412 & 1.8412 & 1.8412 & 1.8412 & 1.8412 \\
\hline
\end{tabular}

TABLE 2: The optimal solution under the three kinds of decision mode with various quality conditions.

\begin{tabular}{|c|c|c|c|c|c|c|c|c|c|}
\hline \multirow{2}{*}{$\begin{array}{l}P \\
(\sigma)\end{array}$} & \multirow{2}{*}{ Variables } & \multirow{2}{*}{$\begin{array}{l}\text { Decentralized- } \\
\text { decision model }\end{array}$} & \multirow{2}{*}{$\begin{array}{c}\text { Centralized-decision } \\
\text { model }\end{array}$} & \multicolumn{6}{|c|}{ Revenue-sharing model } \\
\hline & & & & $\phi=0.25$ & $\phi=0.30$ & $\phi=0.35$ & $\phi=0.40$ & $\phi=0.45$ & $\phi=0.5$ \\
\hline \multirow{7}{*}{$\begin{array}{l}P=0.8860 \\
(\sigma=60)\end{array}$} & $\omega$ & 259.1339 & - & 240.8191 & 237.8191 & 234.8191 & 231.8191 & 228.8191 & 225.8191 \\
\hline & $p_{1}$ & 289.6828 & 257.2513 & 257.2513 & 257.2513 & 257.2513 & 257.2513 & 257.2513 & 257.2513 \\
\hline & $q$ & 151.5858 & 313.7345 & 313.7345 & 313.7345 & 313.7345 & 313.7345 & 313.7345 & 313.7345 \\
\hline & $\lambda$ & 0.0758 & 0.3282 & 0.3282 & 0.3282 & 0.3282 & 0.3282 & 0.3282 & 0.3282 \\
\hline & $\pi_{m}\left(\times 10^{3}\right)$ & 9.0951 & - & 14.118 & 13.177 & 12.236 & 11.294 & 10.353 & 9.4120 \\
\hline & $\pi_{r}\left(\times 10^{3}\right)$ & 4.5842 & - & 4.7060 & 5.6472 & 6.5884 & 7.5296 & 8.4768 & 9.4120 \\
\hline & $\pi_{T}\left(\times 10^{4}\right)$ & 1.3679 & 1.8824 & 1.8824 & 1.8824 & 1.8824 & 1.8824 & 1.8824 & 1.8824 \\
\hline \multirow{7}{*}{$\begin{array}{l}P=0.7218 \\
(\sigma=90)\end{array}$} & $\omega$ & 259.4097 & - & 243.2244 & 240.2244 & 237.22449 & 234.2244 & 231.2244 & 228.2244 \\
\hline & $p_{1}$ & 289.7765 & 258.6586 & 258.6586 & 258.6586 & 258.6586 & 258.6586 & 258.6586 & 258.6586 \\
\hline & $q$ & 151.1173 & 306.7068 & 306.7068 & 306.7068 & 306.7068 & 306.7068 & 306.7068 & \\
\hline & $\lambda$ & 0.0756 & 0.2268 & 0.2268 & 0.2268 & 0.2268 & 0.2268 & 0.2268 & 0.2268 \\
\hline & $\pi_{m}\left(\times 10^{3}\right)$ & 9.0670 & - & 13.802 & 12.882 & 11.962 & 11.041 & 10.121 & 9.20123 \\
\hline & $\pi_{r}\left(\times 10^{3}\right)$ & 4.5559 & - & 4.6006 & 5.5207 & 6.4408 & 7.3610 & 8.2811 & 9.2012 \\
\hline & $\pi_{T}\left(\times 10^{4}\right)$ & 1.3623 & 1.8402 & 1.8402 & 1.8402 & 1.8402 & 1.8402 & 1.8402 & 1.8402 \\
\hline \multirow{7}{*}{$\begin{array}{l}P=0.5889 \\
(\sigma=120)\end{array}$} & $\omega$ & 259.5851 & - & 244.1919 & 241.1919 & 238.1919 & 235.1919 & 232.1919 & 229.1919 \\
\hline & $p_{1}$ & 289.8336 & 259.2609 & 259.2609 & 259.2609 & 259.2609 & 259.26098 & 259.2609 & 259.2609 \\
\hline & $q$ & 150.8319 & 303.6954 & 303.6954 & 303.6954 & 303.6954 & 303.6954 & 303.6954 & 303.6954 \\
\hline & $\lambda$ & 0.0754 & 0.1675 & 0.1675 & 0.1675 & 0.1675 & 0.1675 & 0.1675 & 0.1675 \\
\hline & $\pi_{m}\left(\times 10^{3}\right)$ & 9.0499 & - & 13.666 & 12.755 & 11.844 & 10.933 & 10.022 & 9.1109 \\
\hline & $\pi_{r}\left(\times 10^{3}\right)$ & 4.5387 & - & 4.5554 & 5.4665 & 6.3776 & 7.2887 & 8.1998 & 9.1109 \\
\hline & $\pi_{T}\left(\times 10^{4}\right)$ & 1.3589 & 1.8222 & 1.8222 & 1.8222 & 1.8222 & 1.8222 & 1.8222 & 1.8222 \\
\hline
\end{tabular}


The wholesale price change trend figure

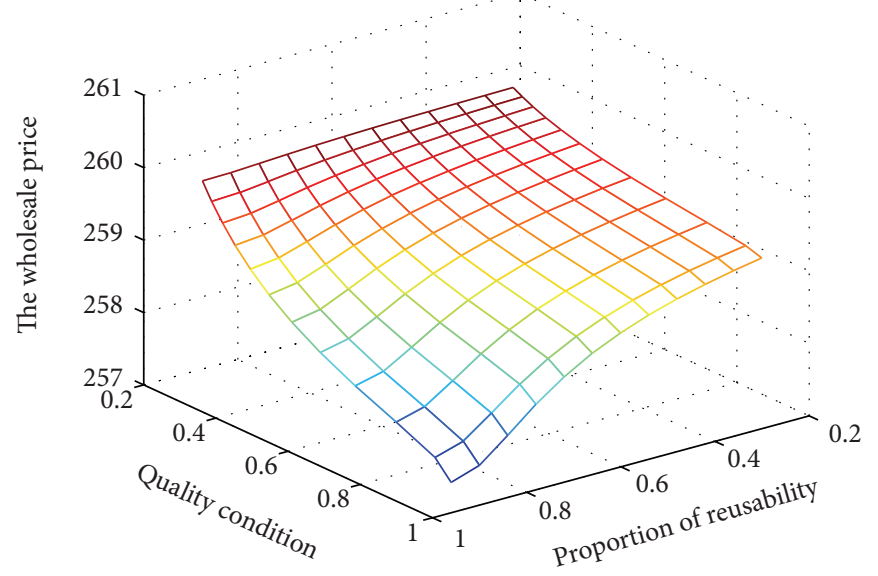

(a)
The retail price change trend figure

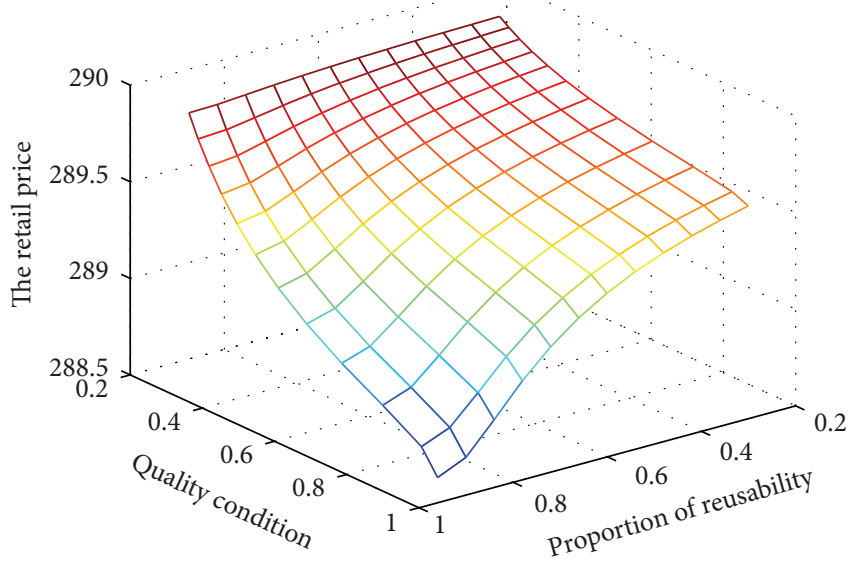

(b)

FIGURE 1: The change trend of price, (a) representing the wholesale price of the manufacturer and (b) representing the retail price of the retailer.

The manufacturer's profit change trend

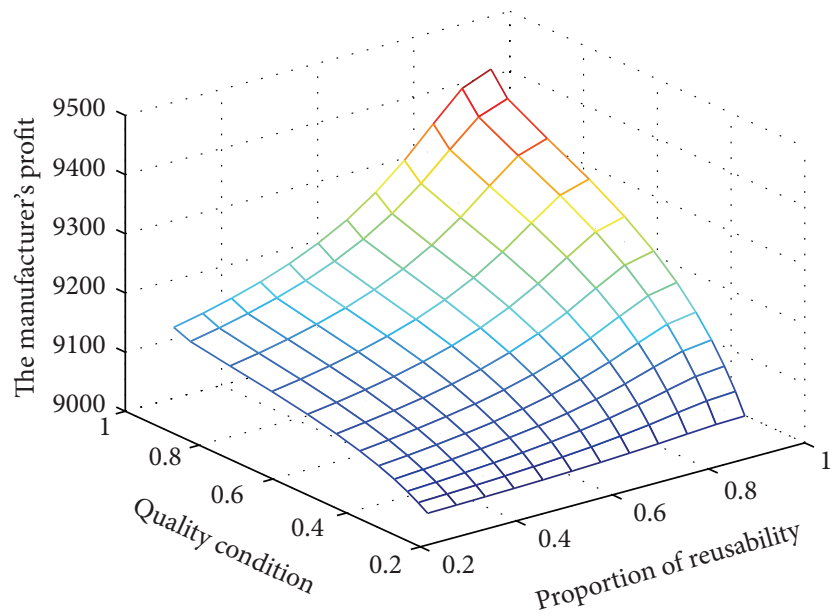

(a)
The retailer's profit change trend

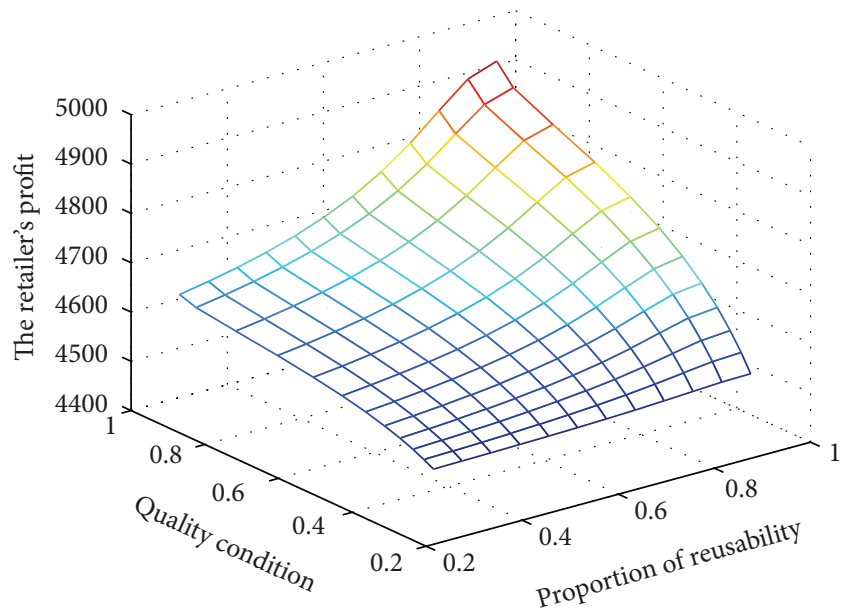

(b)

FIGURE 2: The change trend of profit, (a) representing the profit of the manufacturer and (b) representing the profit of the retailer.

figures about the price and the profit of members with respect to $\rho, P$ are represented as Figures 1 and 2, respectively. Figure 1 shows that the wholesale price and the retail price decrease as the proportion of reusability component designed in new product and quality condition of recovery product increase, respectively. One of reasons is that with the larger proportion of reusability component designed in new product and the better quality condition, the lower the average manufacturing cost, and the manufacturer can obtain more revenue by reducing the wholesale price of product. Correspondingly, the retailer also can gain more sales and more profit by reducing the retail price of product. Figure 2 shows that when the proportion of reusability component designed in new product and quality condition of recovery product increase, respectively, the profits of the members in chain also increase.
Similarly, we can obtain the other change trend figures about the price and the profit and the recycling rate of members in other decision settings; for the sake of space, the figures are omitted.

These conclusions demonstrate that at the begin of designing a new product it is necessary to take into consideration factors such as the facilitation od disassembly, as well as reusability and improved component durability. As the improvement of the proportion of reusability component not only is advantageous to the remanufacturing, which improves the manufacturer revenue, but also is beneficial to the improvement of the retailers' profits and the consumers' welfare and is advantageous to resource recycling and environmental protection. In addition, the manufacturer should pay some attention to control and inspect the quality 
of recycling used product so that the remanufacturing can be implemented well. Thus, investments in reusability and collection are very necessary.

\section{Concluding Remarks}

In CLSC, whether the manufacturer takes part in remanufacturing depends on a crucial factor that whether the remanufacturing can bring forth the economic benefits, that is, whether the remanufacturing cost is lower than the revenue. The manufacturing cost is affected by several factors, including quality condition of recycling product, the proportion of reusability component designed in new product, delivery time, and inventory level. Among these factors, the quality condition of recycling product and the proportion of reusability component designed in new product are two important factors. In a single-manufacturer-single-retailer CLSC in which the manufacturer is responsible for manufacturing and remanufacturing of products, while the retailer is responsible for recycling of the used product and sells only the manufacturer's brand within the product class, this paper investigates the pricing strategies of the decentralized and centralized decision-making mode when the remanufacture cost is random caused by the quality condition of recycling product, the proportion of reusability component designed in new product. The results show that the wholesale price and retail price are negative correlation, while the recycling rate and quantity of recycling product and total profit of supply chain system are positive correlation with the proportion of reusability component designed in new product and quality of recycling product. Moreover, there are conclusions that the wholesale price and retail price are lower while the recycling rate and quantity of recycling product and total profit of supply chain system are higher with centralized decision. Compared to the centralized-decision mode, there exists over $25 \%$ efficiency loss in decentralized-decision setting. The conclusions in this paper reveal that in order to smoothly take implementation of remanufacturing it is needed to consider the proportion of recyclable parts in product design stage and to pay attention to the quality of recovery product in recycling product stage. At the same time, the manufacturer and the retailer should have system idea to coordinate and cooperate each other so that to develop an appropriate wholesale and retail prices to maximize the profit of supply chain members and also to maximize the saving to customers. Then, a winwin situation can be obtained.

This paper assumes that there exists no difference of customers' cognition between the new and remanufacturing product. One may extend it to the case with the consumers' WTP differences. In addition, in case where products are not collected from individual and not inspected individually, this independence might not exist and our results need further justification. Thirdly, incorporating the multiple retailers, risk-averse individuals and the different functions of demand form into our model may be interesting.

\section{Conflict of Interests}

The authors declare that there is no conflict of interests regarding the publication of this paper.

\section{References}

[1] M. C. Georgiadis, P. Tsiakis, P. Longinidis, and M. K. Sofioglou, "Optimal design of supply chain networks under uncertain transient demand variations," Omega, vol. 39, no. 3, pp. 254-272, 2011.

[2] K. L. Donohue, "Efficient supply contracts for fashion goods with forecast updating and two production modes," Management Science, vol. 46, no. 11, pp. 1397-1411, 2000.

[3] D. Huang, H. Zhou, and Q.-H. Zhao, "A competitive multipleproduct newsboy problem with partial product substitution," Omega, vol. 39, no. 3, pp. 302-312, 2011.

[4] H. Y. Chen, Y. H. Chen, C.-H. Chiu, T.-M. Choi, and S. Sethi, "Coordination mechanism for the supply chain with leadtime consideration and price-dependent demand," European Journal of Operational Research, vol. 203, no. 1, pp. 70-80, 2010.

[5] J. Shi, G. Zhang, and J. Sha, "Optimal production planning for a multi-product closed loop system with uncertain demand and return," Computers and Operations Research, vol. 38, no. 3, pp. 641-650, 2011.

[6] M. R. Galbreth and J. D. Blackburn, "Optimal acquisition quantities in remanufacturing with condition uncertainty," Production and Operations Management, vol. 19, no. 1, pp. 6169, 2010.

[7] A. Robotis, T. Boyaci, and V. Verter, "Investing in reusability of products of uncertain remanufacturing cost: the role of inspection capabilities," International Journal of Production Economics, vol. 140, no. 1, pp. 385-395, 2012.

[8] D. Navin-Chandra, "The recovery problem in product design," Journal of Engineering Design, vol. 5, no. 1, pp. 67-87, 1994.

[9] V. D. R. Guide and L. N. van Wassenhove, "Managing product returns for remanufacturing," Production and Operations Management, vol. 10, no. 2, pp. 142-155, 2001.

[10] N. Aras, V. Verter, and T. Boyaci, "Coordination and priority decisions in hybrid manufacturing/remanufacturing systems," Production and Operations Management, vol. 15, no. 4, pp. 528543, 2006.

[11] G. C. Souza and M. E. Ketzenberg, “Two-stage make-to-order remanufacturing with service-level constraints," International Journal of Production Research, vol. 40, no. 2, pp. 477-493, 2002.

[12] G. Ferrer and D. C. Whybark, "Material planning for a remanufacturing facility," Production and Operations Management, vol. 10, no. 1, pp. 112-124, 2001.

[13] L. B. Toktay, L. M. Wein, and S. A. Zenios, "Inventory management of remanufacturable products," Management Science, vol. 46, no. 11, pp. 1412-1426, 2000.

[14] V. D. R. Guide, R. H. Teunter, and L. N. Van Wassenhove, "Matching demand and supply to maximize profits from remanufacturing," Manufacturing and Service Operations Management, vol. 5, no. 4, pp. 303-316, 2003.

[15] A. Robotis, T. Boyaci, and V. Verter, "The effect of remanufacturing on procurement decision for resellers in secondary markets," European Journal of Operational Research, vol. 18, no. 6, pp. 677-686, 2005.

[16] D. Ding and J. Chen, "Coordinating a three level supply chain with flexible return policies," Omega, vol. 36, no. 5, pp. 865-876, 2008.

[17] T. J. Xiao, X. X. Yan, and J. B. Zhao, "Coordination of a supply chain with advertising investment and allowing the second ordering," Technology and Investment, vol. 1, no. 3, pp. 191-200, 2010. 
[18] J. Xie and J. C. Wei, "Coordinating advertising and pricing in a manufacturer-retailer channel," European Journal of Operational Research, vol. 197, no. 2, pp. 785-791, 2009.

[19] Y. X. Zhao, S. Y. Wang, T. C. E. Cheng, X. Q. Yang, and Z. M. Huang, "Coordination of supply chains by option contracts: a cooperative game theory approach," European Journal of Operational Research, vol. 207, no. 2, pp. 668-675, 2010.

[20] V. D. R. Guide, "Production planning and control for remanufacturing: industry practice and research needs," Journal of Operations Management, vol. 18, no. 4, pp. 467-483, 2000.

[21] K. Inderfurth, S. D. P. Flapper, A. J. D. Lambert, C. P. Pappis, and T. G. Voutsinas, "Production planning for product recovery management," in Reverse Logistic: Quantiative Models for Closed-Loop Supply Chain, R. Dekker, M. Fleischmann, K. Inderfurth, and L. N. Van Wassenhove, Eds., Springer, Berlin, Germany, 2004.

[22] Y. Feng and S. Viswanathan, "A new lot-sizing heuristic for manufacturing systems with product recovery," International Journal of Production Economics, vol. 133, no. 1, pp. 432-438, 2011.

[23] M. S. Pishvaee, M. Rabbani, and S. A. Torabi, "A robust optimization approach to closed-loop supply chain network design under uncertainty," Applied Mathematical Modelling, vol. 35, no. 2, pp. 637-649, 2011.

[24] V. Ravi, "Selection of third-party reverse logistics providers for end-of-life computers using TOPSIS-AHP based approach," International Journal of Logistics Systems and Management, vol. 11, no. 1, pp. 24-37, 2012.

[25] E. A. Van der Laan, G. Kiesmüller, R. Kuik, D. Valchos, and R. Dekker, "Stochastic Inventory control for product recovery change chain to chains," in Reverse Logistic: Quantiative Models for Closed-Loop Supply Chain, R. Dekker, M. Fleischmann, K. Inderfurth, and L. N. Van Wassenhove, Eds., Springer, Berlin, Germany, 2004.

[26] S.-L. Chung, H.-M. Wee, and P.-C. Yang, "Optimal policy for a closed-loop supply chain inventory system with remanufacturing," Mathematical and Computer Modelling, vol. 48, no. 5-6, pp. 867-881, 2008.

[27] R. C. Savaskan, S. Bhattacharya, and L. N. van Wassenhove, "Closed-loop supply chain models with product remanufacturing," Management Science, vol. 50, no. 2, pp. 239-252, 2004.

[28] R. C. Savaskan and L. N. Van Wassenhove, "Reverse channel design: the case of competing retailers," Management Science, vol. 52, no. 1, pp. 1-14, 2006.

[29] G. Ferrer and J. M. Swaminathan, "Managing new and remanufactured products," Management Science, vol. 52, no. 1, pp. 1526, 2006.

[30] S. Webster and S. Mitra, "Competitive strategy in remanufacturing and the impact of take-back laws," Journal of Operations Management, vol. 25, no. 6, pp. 1123-1140, 2007.

[31] M. Fleischmann, J. M. Bolemhof-Ruwaard, P. Beullens, and R. Dekker, "Reverse logistic network design," in Reverse Logistics: Quantitative Models for Closed-Loop Supply Chains, R. Dekker, M. Fleischmann, K. Inderfurth, and L. N. Van Wassenhove, Eds., Springer, Berlin, Germany, 2004.

[32] Y. Liang, S. Pokharel, and G. H. Lim, "Pricing used products for remanufacturing," European Journal of Operational Research, vol. 193, no. 2, pp. 390-395, 2009.

[33] C. Lee, M. Realff, and J. Ammons, "Integration of channel decisions in a decentralized reverse production system with retailer collection under deterministic non-stationary demands," Advanced Engineering Informatics, vol. 25, no. 1, pp. 88-102, 2011.

[34] W.-M. Ma, Z. Zhao, and H. Ke, "Dual-channel closed-loop supply chain with government consumption-subsidy," European Journal of Operational Research, vol. 226, no. 2, pp. 221-227, 2013.

[35] H. Fallah, H. Eskandari, and M. S. Pishvaee, "Competitive closed-loop supply chain network design under uncertainty," Journal of Manufacturing Systems, 2015.

[36] M. Denizel, M. Ferguson, and G. G. C. Souza, "Multiperiod remanufacturing planning with uncertain quality of inputs," IEEE Transactions on Engineering Management, vol. 57, no. 3, pp. 394-404, 2010.

[37] M. Ferguson, V. D. R. Guide Jr., E. Koca, and G. C. Souza, “The value of quality grading in remanufacturing," Production and Operations Management, vol. 18, no. 3, pp. 300-314, 2009.

[38] Q. Qiang, K. Ke, T. Anderson, and J. Dong, “The closed-loop supply chain network with competition, distribution channel investment, and uncertainties," Omega, vol. 41, no. 2, pp. 186194, 2013.

[39] N. Aras, T. Boyaci, and V. Verter, "The effect of categorizing returned products in remanufacturing," IIE Transactions, vol. 36, no. 4, pp. 319-331, 2004.

[40] C. Zikopoulos and G. Tagaras, "Impact of uncertainty in the quality of returns on the profitability of a single-period refurbishing operation," European Journal of Operational Research, vol. 182, no. 1, pp. 205-225, 2007.

[41] G. P. Cachon and M. A. Lariviere, "Supply chain coordination with revenue-sharing contracts: strengths and limitations," Management Science, vol. 51, no. 1, pp. 30-44, 2005.

[42] W.-G. Zhang, J. H. Fu, H. Y. Li, and W. J. Xu, "Coordination of supply chain with a revenue-sharing contract under demand disruptions when retailers compete," International Journal of Production Economics, vol. 138, no. 1, pp. 68-75, 2012.

[43] K. Govindan and M. N. Popiuc, "Reverse supply chain coordination by revenue sharing contract: a case for the personal computers industry," European Journal of Operational Research, vol. 233, no. 2, pp. 326-336, 2014.

[44] C. Shi, G. L. Zhou, X. Yan, Z. Zhang, and Y. Ma, "Downside-risk based closed-loop supply chain coordinated by two-third-party collecting logistics," Chinese Journal of Management, vol. 11, no. 10, pp. 1520-1527, 2014.

[45] J. H. Mortimer, "The effects of revenue-sharing contracts on welfare in vertically separated markets: evidence from the Video rental industry," Working Paper, University of California, Los Angeles, Calif, USA, 2002.

[46] J. von Neumann and O. Morgenstern, Theory of Games and Economic Behavior, Princeton University Press, Princeton, NJ, USA, 2nd edition, 1953.

[47] J. W. Pratt, "Risk aversion in the small and in the large," Econometrica, vol. 32, no. 1-2, pp. 122-136, 1964. 


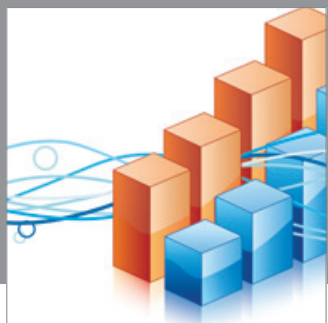

Advances in

Operations Research

mansans

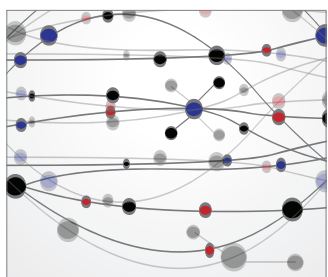

The Scientific World Journal
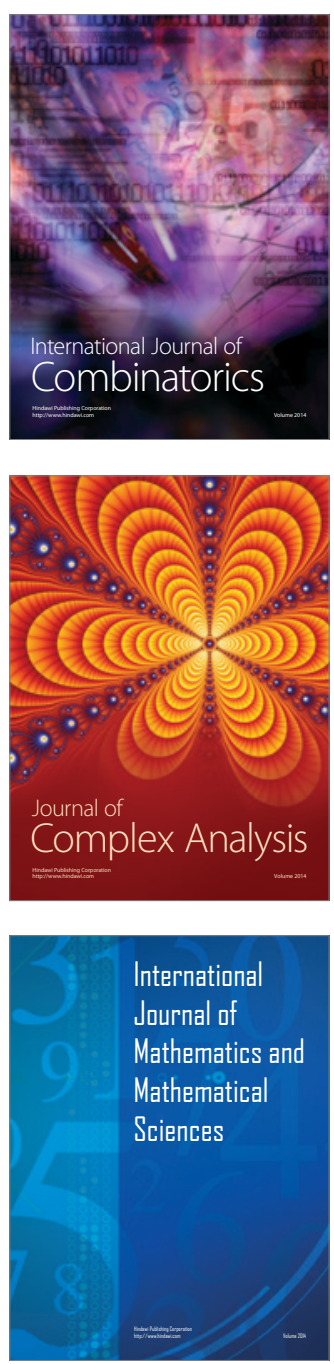
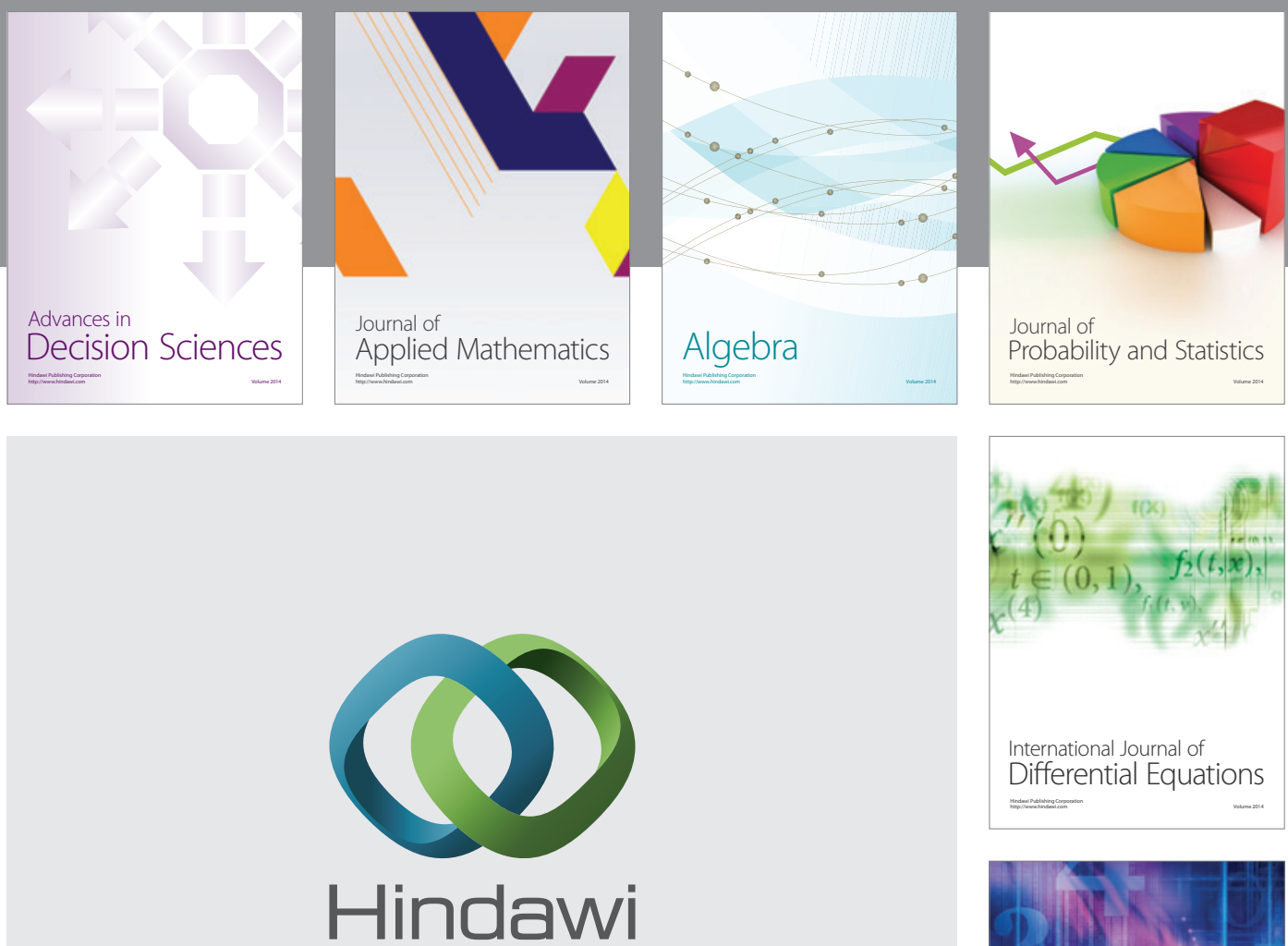

Submit your manuscripts at http://www.hindawi.com
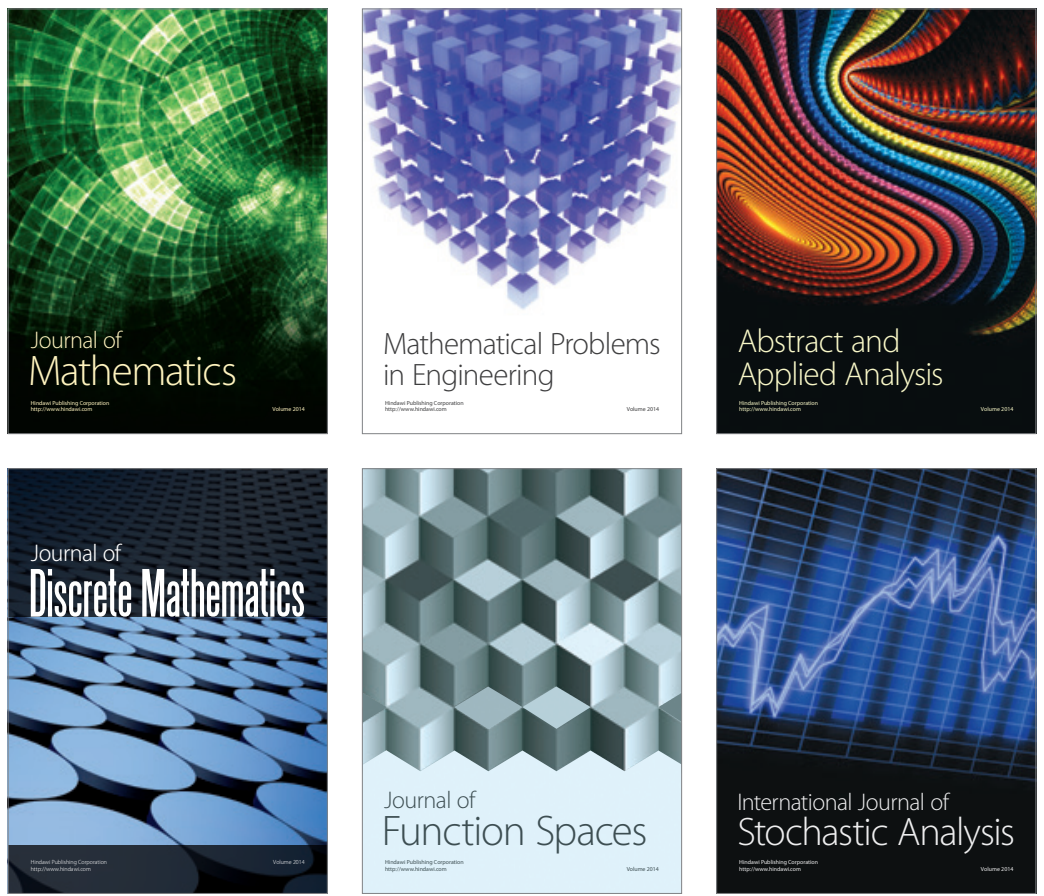

Journal of

Function Spaces

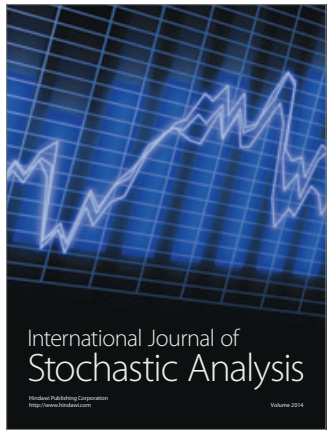

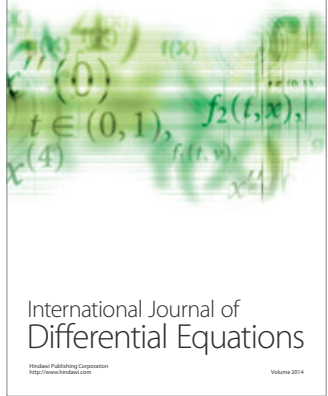
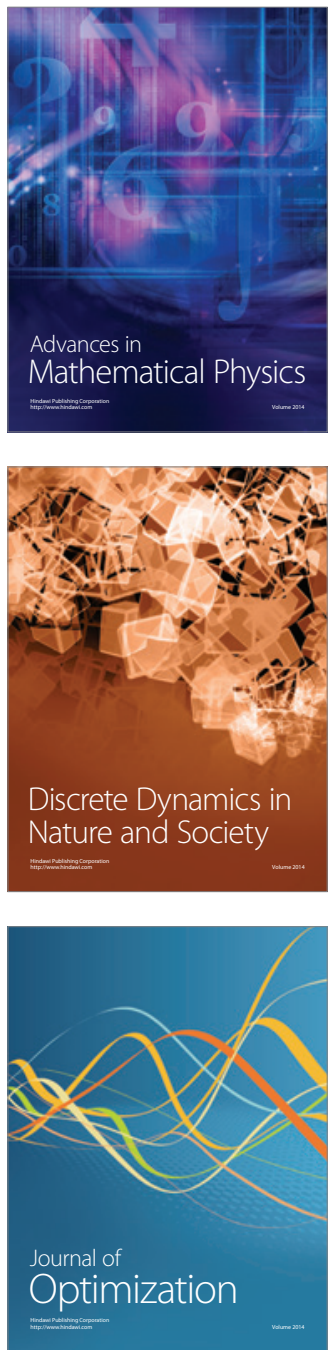